\title{
Poemas de Tomas Tranströmer
}

Tradução de José Eduardo Reis

Universidade de Trás-os-Montes e Alto Douro - ILC

\begin{abstract}
Allegro
Toco Haydn depois de um dia negro

e sinto um calor simples nas mãos.

O teclado está ansioso. Os martelos soam temperados.

0 som é verde, vivíssimo, tranquilo.

O som diz que a liberdade existe,

que alguém não paga o imposto de César.

Meto as mãos nos meus bolsos de Haydn

e finjo deitar um olhar frio ao mundo.

Faço içar a bandeira de Haydn - ela indica:

"Não nos renderemos. Mas queremos paz."

A música é uma casa de vidro na encosta

onde voam pedras, se quebram pedras.

E as pedras quebram-se pelos vidros adentro

mas a casa continua de pé, inteira.
\end{abstract}

In: Half-finished heaven / O Céu por Acabar (1962), a partir da versão inglesa de May Swenson e Leif Sjöberg 


\section{Dó Maior}

Quando desceu à rua depois do encontro

o ar rodopiava de neve.

0 inverno chegara

enquanto estiveram juntos.

A noite brilhava branca.

Caminhou leve de alegria.

A cidade inteira em declive.

Os sorrisos que passavam -

sorriam todos atrás de colarinhos vincados.

Era de graça!

E todos os pontos de interrogação começavam a cantar o ser de Deus.

Foi isso que pensou.

Uma música surgiu

e a passos largos

caminhava num turbilhão de neve.

Tudo a caminho da nota dó.

Um trémulo compasso em direcção a dó.

Uma hora acima dos tormentos.

Era fácil!

Sorriam todos atrás de colarinhos vincados.

In: Alf-Finished Heaven / O Céu por acabar (1962),

a partir da versão inglesa de Robin Fulton 


\section{Um artista no Norte}

Eu Edward Grieg passeei-me como um homem livre entre os homens.

De trato fácil li jornais viajei por aqui e por ali.

Regi a orquestra.

0 auditório com as luzes cintilando de triunfo como um navio

de comboios

quando se põe em marcha.

Levei-me para aqui para me fechar no silêncio.

É pequeno o meu estúdio.

O piano aninhado como a andorinha no beiral.

O mais das vezes as belas e íngremes encostas nada dizem.

Não há saída possível

mas às vezes uma pequena fresta abre-se

e uma luz incide directamente do assombro.

Reduzir!

E as pancadas dos martelos na montanha vêm

vêm

vêm

vêm numa noite de primavera ao nosso quarto

disfarçadas de batimentos do coração.

Um ano antes de morrer lançarei quatro hinos para chegarem até Deus.

Mas é aqui que tudo começa.

Uma canção do que está próximo.

Do que está próximo.

O nosso campo de batalha 
onde nós os Ossos dos Mortos

lutamos para nos tornarmos vivos.

In : Bells and Tracks / Ecos e vestígios (1966),

a partir da versão inglesa de Robin Fulton

\section{Música lenta}

A casa hoje por abrir. 0 sol entra a jorros pelas janelas

e aquece o tampo da secretária

que é sólida capaz de carregar com o destino dos outros.

Andamos hoje ao ar livre pela longa e larga encosta.

Há quem se vista de negro. Se ficares ao sol e fechares os olhos

vais sentir o vento a levar-te lentamente.

É raríssimo vir até junto ao mar. Vim agora

entre enormes pedras com um lado tranquilo.

Pedras que passo a passo recuam para fora do mar.

In : Bells and Tracks / Ecos e vestígios (1966),

a partir da versão inglesa de Robert Bly. 


\section{Schubertiana}

\section{1}

Longe de Nova York, um lugar alto donde se avistam as casas em que oito milhões de seres vivos habitam.

A cidade gigante para aqueles lados é uma longa deriva cintilante, uma galáxia em espiral vista de lado.

Dentro da galáxia, chávenas de café são arrastadas pela secretária, janelas de armazém suplicam, um turbilhão de sapatos que não deixam nenhum rasto.

O fogo escapa-se ao alto, portas de elevador fecham-se silenciosamente por detrás de portas fechadas a sete chaves, um volume cheio de vozes. Corpos tombados dormitam em carros subterrâneos, catacumbas em movimento.

Sei também - estatísticas à parte - que neste momento nalguma sala mais abaixo toca-se Schubert, e que para essa pessoa as notas são mais reais que tudo o resto.

\section{2}

As imensas planícies sem árvores do cérebro humano acabaram por se dobrar e redobrar até ficarem do tamanho de um punho. Em Abril a andorinha regressa ao ninho do ano anterior sob o beiral precisamente no mesmo celeiro precisamente no mesmo distrito.

Voa do Transval, passa o equador, voa durante seis semanas por cima de dois continentes, navega com precisão para este ponto extenuado na massa da terra.

E o homem que reúne os sinais de uma vida inteira nalguns acordes vulgares para cinco músicos de cordas aquele que tem um rio para atravessar pelo buraco duma agulha é um jovem roliço de Viena, os amigos chamam-no 
"O Cogumelo", que dormia de óculos postos

e se punha pelas manhãs pontualmente à escrivaninha.

Quando o fazia centopeias magníficas desatavam a mover-se

sobre a página.

\section{3}

Tocam os cinco instrumentos. Volto para casa pelo calor dos bosques

onde a terra se distende sob os meus pés,

enrolo-me como alguém ainda por nascer, adormeço, vagueio imponderável

para o futuro, sinto de súbito que as plantas estão

a pensar.

\section{4}

Quanto nos leva cada minuto a acreditar que vivemos

para não nos esvairmos pela terra adentro!

A acreditar em massas de neve agarrando-se à superfície das rochas sobre a cidade.

A acreditar nas promessas não faladas e no sorriso da concórdia, a acreditar que o telegrama não é connosco, e que o súbito golpe do machado não vem por dentro.

A acreditar nos eixos que nos levam pela estrada fora entre abelhas de aço trezentas vezes ampliadas.

Mas nada disso merece de facto a nossa crença.

Os cinco instrumentos de cordas dizem que podemos ser levados a acreditar noutra coisa qualquer, e por instantes acompanham-nos na estrada.

Tal qual a lâmpada que se apaga nas escadas, e a mão seguindo - acreditando - no corrimão cego que faz o seu caminho pela escuridão adentro.

\section{5}

Juntamo-nos ao banco do piano e tocamos a quatro mãos em Fá menor, dois condutores para o mesmo carro, parece um pouco 
ridículo.

As mãos parecem movimentar pesos feitos de sons

para diante e para trás, parecem movimentar pesos pesados

numa tentativa de mudar a grande escala do temível equilíbrio:

felicidade e sofrimento pesam exactamente o mesmo.

Annie disse, "Esta música é tão heróica”, e tem razão.

Mas aqueles que lançam um olhar invejoso ao homem de acção, aqueles que

por dentro se desprezam por não serem assassinos,

não se descobrem nesta música.

$\mathrm{E}$ as pessoas que compram e vendem outras pessoas, que acreditam

que não há ninguém que não possa ser comprado, não se descobrem aqui.

Não é a sua música. A longa linha melódica que permanece igual

entre todas as suas variações, por vezes brilhante e delicada,

por vezes áspera e poderosa, rastro de caracol e arame

de aço.

O obstinado sussurro deste instante que está connosco

para cima para

o fundo.

In: Truth Barriers / Verdade Sitiada (1978),

a partir da versão inglesa de Robert Bly 


\section{Gôndola Triste \# 2}

\section{1}

Dois velhos, sogro e genro, Liszt e Wagner, estão hospedados perto do Grande Canal juntos com a mulher inquieta casada com o Rei Midas o homem que transforma tudo o que toca em Wagner.

0 frio verde glacial do mar faz o seu caminho pelos soalhos do palácio.

Wagner está um farrapo, o seu famoso perfil de roberto está mais enrugado que nunca o rosto uma bandeira branca.

A gôndola vai carregada com três vidas, dois bilhetes de ida e volta e um de ida.

\section{2}

Uma das janelas do palácio abre-se de súbito, lá dentro as pessoas assombram-se com a repentina corrente de ar.

Cá fora surge nas águas a gôndola do lixo conduzida

por dois bandidos de um só remo.

Liszt compôs uns acordes tão pesados que têm

de ser enviados

ao instituto mineralógico de Pádua para análise.

Meteoritos!

demasiado pesados para se firmarem, só podem ir ao fundo, ao fundo, a pique para o futuro, para os anos dos camisas castanhas.

A gôndola vai carregada com as pedras submissas do futuro. 
3

Frestas, abrindo-se em 1990

25 de Março. Ansiedade pela Lituânia.

Sonhei que visitava um hospital grande.

Sem pessoal médico. Todos doentes.

No mesmo sonho uma menina recém-nascida

que dizia frases completas.

\section{4}

Ao lado do genro, que é um senhor de idade, Liszt

é um Grand Seigneur roído pela traça.

É um disfarce.

0 abismo que experimenta e rejeita diferentes máscaras escolheu

esta para ele.

O abismo que deseja entrar, visitar os humanos sem

mostrar o rosto.

\section{5}

O abade Liszt está habituado a carregar a mala

pela neve suja e ao sol

mas chegada a hora da morte ninguém há-de ir ter com ele à

estação.

Uma brisa quente saturada de conhaque leva-o a sair

a meio de um dever.

Os deveres nunca o largam.

Duas mil cartas por ano!

0 aluno que tem de escrever a palavra mal soletrada cem

vezes antes de ir para casa.

A gôndola vai carregada de vida, é simples e negra. 


\section{6}

De novo 1990.

Sonhei que andei 200 quilómetros para nada.

Tudo aumentou de volume. Pardais grandes

como galinhas cantavam ensurdecedores.

Sonhei que desenhava teclas de piano

na mesa da cozinha. Em silêncio tocava nelas.

Os vizinhos entraram para ouvir.

\section{7}

O teclado que se manteve em silêncio ao longo de todo o Parsifal

(mas que o escutou) tem finalmente direito a dizer algo.

Suspiros ... sospiri ...

Liszt ao tocar mantém esta noite o pedal marítimo em baixo

para que o poder verde do mar suba pelo soalho acima

e se misture com as pedras do edifício.

Boa noite, lindo abismo!

A gôndola vai carregada de vida, é simples e negra.

\section{8}

Sonhei que começavam hoje as aulas e que cheguei tarde.

Na sala todos usavam uma máscara branca.

Impossível dizer quem era o professor.

In: The Sorrow Gondola / Gôndola Triste (1996), a partir da versão inglesa de Robin Fulton

Nota: No final de 1882, princípios de 1883, Liszt visitou a sua filha Cosima e o marido, Richard Wagner, em Veneza. Wagner morreu uns meses depois. As duas peças para piano publicadas com o título Gôndola Triste foram compostas por essa altura. 


\section{Prelúdios}

\section{1}

Recuo diante de uma coisa que se arrasta de lado pela

tempestade de neve.

Fragmento do que está para vir.

Uma parede esboroando-se. Uma coisa sem olhos. Rija.

Um rosto de dentes.

Uma parede solitária. Ou é uma casa que ali está

embora a não consiga ver?

O futuro ... um exército de casas vazias

tacteando o caminho pela neve que cai.

\section{2}

Duas verdades aproximam-se uma da outra. Uma vem de dentro,

outra de fora,

e onde se encontram é possível ter um indício

de nós.

O homem que vê o que está para acontecer grita desvairado

"Alto!

Seja o que for, desde que não tenha de me conhecer a mim mesmo."

E há um barco que se quer amarrar à terra - insiste mesmo

aqui -

de facto insistirá ainda milhares de vezes.

Da escuridão dos bosques surge um longo arpão,

irrompe pela janela aberta

entre os convidados que aquecem dançando. 


\section{3}

0 apartamento onde vivi metade da minha vida tem de ficar vazio. Já não tem nada. A âncora tem de subir - apesar do peso da tristeza, é o apartamento mais leve de toda a cidade. A verdade não precisa de nenhuma mobília. A minha vida fechou agora um grande círculo e voltou ao ponto de partida: uma sala vazia. Coisas que nela vivi tornam-se visíveis nas paredes iguais a pinturas egípcias, murais duma câmara funerária. Imagens esbatendo-se devido a uma luz excessiva. As janelas mais largas. 0 apartamento vazio é um grande telescópio apontado ao céu. É silencioso como um ritual Quaker. Tudo o que podes escutar são as pombas nas traseiras, o arrulhar delas.

In : Night Vision / Visão da Noite (1970),

a partir da versão inglesa de Robert Bly

\section{Solidão}

\section{I}

Aqui, estive a ponto de morrer numa noite de Fevereiro.

O carro patinou no gelo, derrapou de lado e seguiu

na faixa contrária. Os carros aproximando-se -

os seus faróis - cada vez mais perto.

O meu nome, as minhas filhas, o meu emprego

desprenderam-se e ficaram para trás em silêncio

cada vez mais para trás. Eu estava anónimo,

como uma criança num pátio de colégio cercada de inimigos.

Era poderosa a luz do tráfego aproximando-se.

Iluminava-me à medida que girava e girava

o volante num medo transparente agitado como clara de ovo. 
Os segundos dilatavam-se - ocupando mais espaço engrandeciam como edifícios de hospital.

Podia-se quase ficar à vontade

e um tudo nada descontraído

antes do choque se dar.

Então surgiu terra firme: veio em socorro um grão de areia

ou uma rajada súbita de vento. 0 carro agarrou-se

derrapou, atravessou a estrada.

Elevou-se um poste e quebrou-se - um som vibrante

juntou-se à escuridão.

Até que chegou o silêncio. Sentado e seguro pelo cinto

vi alguém caminhar no turbilhão da neve

para ver o que restava de mim.

\section{II}

A caminhar durante horas

pelos campos gelados da Suécia

não consegui ver ninguém.

Noutras partes do mundo

pessoas nascem, vivem e morrem

em perpétua multidão.

Ser constantemente visível - viver

num enxame de olhos -

deixa marcas no rosto.

Sulcos revestidos de pó.

O murmúrio que sobe e desce

enquanto dividem entre si 
o céu, as sombras, os grãos de areia.

Tenho de estar a sós

dez minutos pela manhã

dez minutos pela tarde.

- Sem fazer nada.

Todos fazem fila à porta de todos.

Muitos.

Um.

In: Resonance and Footprints / Ecos e Vestígios (1966), a partir da versão inglesa de Robert Bly

\section{Funchal}

0 restaurante na praia, simples, para se comer peixe, uma cabana feita por sobreviventes de um naufrágio. Muitos afastam-se da porta, mas não as rajadas que vêem do mar. Uma sombra de pé na cabana cheia de fumo está a fritar dois peixes seguindo uma receita antiga da Atlântida, pequenas explosões de alho, azeite derramado sobre rodelas de tomate. Todos os pedaços dizem que o oceano nos quer bem, um murmúrio dos abismos.

Ela e eu olhamo-nos. É como subir floridas encostas escarpadas sem sentir nenhum cansaço. Caminhamos ao lado de animais, somos bem-vindos, não envelhecemos. Mas passámos por tanta coisa juntos ao longo dos anos, lembramo-nos bem disso, anos também em que não valemos grande coisa (como quando fizemos fila para dar sangue ao gigante cheio de saúde - ele ordenou uma transfusão), coisas que nos teriam separado se não nos tivessem aproximado, e coisas que esquecemos juntos - mas que não nos esqueceram! Tornaram-se pedras, de sombra e de luz. 
Pedras num mosaico desfeito. E agora acontece: as peças voam lado a lado, o mosaico é visível. Está à nossa espera, a brilhar da parede do quarto do nosso hotel, um desenho terno e violento, talvez um rosto, não o vemos inteiro enquanto tiramos as roupas.

Saímos ao anoitecer. A mão azul escura e maciça do molhe estende-se pelo mar adentro. Entrámos num turbilhão humano, amavelmente empurrados entre delicadas tiranias, todos tagarelando naquela língua estrangeira. "Nenhum homem é uma ilha". Com eles ganhamos forças, connosco também. Com o que está em nós que o outro não consegue ver. 0 que só se pode encontrar a si. 0 paradoxo mais íntimo, a garagem flor, a clarabóia para a boa escuridão. Uma bebida com gás num copo vazio. Um amplificador que emite silêncio. Um caminho que aumenta a cada passo. Um livro que só se pode ler no escuro.

In: Truth Barriers / Verdade Sitiada (1978), a partir da versão inglesa de Robin Fulton

\section{Memórias que me observam}

Manhã de Junho, cedo de mais para acordar, tarde de mais para adormecer.

Tenho de sair - é densa a folhagem das memórias, perseguem-me com o seu olhar.

Não se deixam ver, misturam-se todas com o fundo, verdadeiros camaleões.

Tão perto estão que as ouço respirarem aqui onde o canto do pássaro ensurdece.

In : The Wild Market Square / Feira Livre (1983), a partir da versão inglesa de Robin Fulton 


\section{A viagem}

Na estação subterrânea.

Uma multidão entre placares

num pasmo de luz morta.

O comboio parou e recolheu

rostos e portefólios

Depois a escuridão. Sentámo-nos

nas carruagens como estátuas,

arrastados pelas cavernas.

Restrição, sonhos, restrição.

Em estações abaixo do nível do mar

vendiam-se notícias da escuridão.

Pessoas movendo-se tristemente

silenciosas debaixo do mostrador dos relógios.

O comboio carregando

roupas e almas.

Olhares em todas as direcções

na viagem pela montanha.

Nenhuma mudança.

Junto à superfície começa

um zunido de abelhas - liberdade.

Saímos da terra.

A terra por uma vez bateu

asas e ficou quieta debaixo

de nós, estirada e verde.

Espigas de milho esvoaçavam 
por cima das plataformas.

Terminal - eu

prossegui mais além.

Comigo quantos estavam? Quatro,

cinco, não mais.

Casas, estradas, céus,

enseadas azuis, montanhas

abrindo as suas janelas.

In: Half-finished heaven / O Céu por Acabar (1962), a partir da versão inglesa de Robin Fulton

\section{Anémonas Azuis}

Maravilhar-se - nada mais fácil. É um dos truques mais antigos da terra e da primavera: as anémonas azuis. São à sua maneira inesperadas. Despontam entre o castanho da esteva do ano que passou em sítios onde nunca se pousa o olhar. Cintilam e flutuam, sim, flutuam e isso vem da sua cor. Aquele vivo azul violeta não pesa nada. Aqui é o êxtase, mas em voz baixa. "Carreira" irrelevante! "Poder" e "publicidade" - ridículo! Devem ter dado uma grande recepção em Nineveh com pompa e trompas ao alto. Uma festa de arromba. E por cima daquelas cabeças os candelabros coroados de cristal pendendo como abutres de vidro. Em lugar da estridência desse cárcere, as anémonas abrem uma passagem secreta para a verdadeira celebração, que é tranquila, como a morte.

In : The Wild Market Square / Feira Livre (1983), a partir da versão inglesa de Robin Fulton 


\section{Vermeer}

Não é um mundo seguro. 0 ruído começa ali,

do outro lado da parede

onde está a estalagem

com risos e refregas, rixas de dentes, lágrimas,

o seu retinir de sinos

e o cunhado insano, o assassino, que faz com

que na sua presença todos sintam temor.

A grande explosão e o tropel do resgate que chega atrasado

os barcos exibindo-se nos canais, o dinheiro correndo

para o bolso do homem malvado

ultimatos atrás de ultimatos

flores encarnadas abertas ressoando premonições de guerra.

E exactamente dali através da parede

para o estúdio de luz

e os segundos a quem autorizaram viver séculos.

Quadros com nomes próprios “A Lição de Música”

ou "Mulher de Azul Lendo uma Carta".

Está grávida de oito meses, dois corações que batem dentro dela.

Na parede atrás vê-se um mapa enrugado da Terra Incognita.

Respira apenas. Um material azul que se desconhece está pregado às cadeiras.

Os rebites de ouro voaram com incrível rapidez

e pousaram ali abruptamente

como se não fossem outra coisa senão silêncio.

Os ouvidos zumbem, talvez do abismo talvez do cume.

É a pressão do outro lado da parede

A pressão que faz flutuar os factos

e firmar o pincel. 
Atravessar as paredes faz sofrer, faz adoecer

mas não temos outra escolha.

0 mundo é um. Mas as paredes ....

As paredes são parte de ti -

Ou se sabe ou não se sabe embora seja assim para todos

excepto para as crianças. Para elas não há paredes.

O céu limpo tomou o seu lugar e encostou-se à parede.

É como uma prece ao vazio.

E o vazio volta o seu rosto para nós

E murmura

"Não sou vazio, sou aberto".

In: For Living and Dead /Para Vivos e Mortos (1989), a partir da versão inglesa de Robert Bly

\section{Tempestade}

O homem que passeia de súbito dá com o velho

carvalho gigante, um alce transformado em pedra com

a sua enorme armadura contra o verde escuro da muralha

baixa do oceano.

Tempestade do norte. As sorveiras bravas

estão quase maduras. De noite acordado ele

escuta as constelações muito acima do carvalho

saltando nos seus cadeirais.

In: 17 poems /17 poemas (1954),

a partir da versão inglesa de Robert Bly 


\section{Pós-convalescença}

O miúdo doente.

Fechado em si numa visão

com a língua dura como um chifre.

Senta-se de costas voltado para uma seara num quadro.

A ligadura à volta do queixo parece ser a de uma múmia.

Os óculos são grossos, de mergulhador. Não há resposta e nada

é repentino como um telefone que toca a meio da noite.

Mas ali o quadro. Uma paisagem que nos faz sentir

em paz mesmo se o trigo é uma tempestade de ouro.

Azul, terrível azul e nuvens em andamento. Debaixo nas ondas

amarelas

camisas brancas velejando: malhadores - não projectam sombras.

Na extremidade do campo um homem parece olhar nesta direcção.

Um chapéu largo esconde o seu rosto na sombra.

Parece olhar para a figura negra aqui na sala, como

se quisesse ajudar.

A pouco e pouco o quadro alarga-se, começa a abrir por detrás

do miúdo que está doente

e mergulhado em si. Lança faúlhas e faz ruído. Cada

espiga de trigo irradia luz para o despertar!

0 outro homem - no trigo - faz um sinal.

Aproxima-se.

Ninguém se apercebe.

In: Secrets on the Road / Segredos na Estrada (1958),

a partir da versão inglesa de Robert Bly 


\section{Nocturno}

Conduzo por uma aldeia à noite, casas que saltam

diante das luzes - acordaram agora, querem beber um copo.

Casas, celeiros, placas de indicação, caminhos sem ninguém

regressam à vida. Seres humanos dormem:

alguns podem dormir em paz, outros têm rostos tensos

como num treino duro para a eternidade.

Não ousam deixar-se ir mesmo em sono solto.

Como cancelas baixas esperam enquanto o mistério vai desfilando.

A estrada passa uma longa temporada fora da cidade pela

floresta.

Árvores, árvores silentes num pacto entre elas.

Têm uma cor melodramática, como um incêndio.

Como é nítida cada uma das folhas. Seguem-me no caminho para casa.

Deito-me por ali para dormir, vejo imagens desconhecidas

e sinais esboçando-se atrás das pálpebras

no muro da escuridão. Pela ranhura entre a vigília e o sono

uma enorme letra esforça-se por entrar sem grande sucesso.

In: Half-finished heaven / O Céu por Acabar (1962),

a partir da versão inglesa de Robert Bly 


\section{Acerca da História}

Num dia de Março caminhei para escutar até à beira do lago.

O gelo era azul como o céu. E quebrava-se ao sol.

O sol sussurrava a um microfone debaixo do gelo.

Há um fervilhar e borbotar. De longe parece uma folha de papel a ser amarrotada.

Tudo isto é como a História: o nosso presente. Descemos nele, escutamos.

\section{II}

Conferências são como ilhas instáveis e voadoras.

Epílogo: uma frágil ponte suspensa de compromissos.

0 tráfego inteiro passa por cima daquela ponte debaixo de estrelas, debaixo de faces de crianças ainda por nascer, pálidas, abandonadas, sem nome como grãos de arroz.

\section{III}

Em 1926, Goethe visitou a África disfarçado de Gide e reparou nisso.

Há rostos que se tornam mais nítidos pelo que vêem depois da morte. Ao chegarem notícias diárias da Argélia pela rádio vi uma casa enorme e todas as janelas da casa eram escuras excepto uma. Era dessa mesma que o rosto de Dreyfus olhava.

\section{IV}

Radical e Reaccionário vivem juntos como num casamento miserável, diminuídos um pelo outro, encostados um ao outro. Mas nós, os seus filhos, temos de encontrar o nosso caminho. Cada problema exige a sua linguagem privada. 
Por qualquer vereda em que haja um traço de verdade, caminhem. V

Num baldio não longe das leiras

há meses que está um jornal aberto cheio de notícias.

Envelhece devido ao dia e à noite, chuva e sol.

Está a ponto de se tornar uma planta, um repolho. Está

a unir-se à terra

como uma memória antiga que se transforma gradualmente em ti.

In: Resonance and Footprints / Ecos e Vestígios (1966), a partir da versão inglesa de Robert Bly

\section{A estante}

Foi levada do apartamento após a sua morte. Por alguns dias ficou vazia antes de lhe colocar os livros, todos os de capa dura, os pesados. Sem saber como, deixei que nela se derramasse alguma terra do cemitério. Algo veio debaixo, elevou-se gradualmente, implacavelmente como uma enorme coluna de mercúrio. Um homem não pode virar a cara.

Volumes escuros, rostos fechados. Pareciam os rostos daqueles argelinos que vi na fronteira em Friedrichstrasse à espera que a Polícia do Povo da Alemanha do Leste carimbasse os seus passaportes. $\mathrm{O}$ meu passaporte também ficou por muito tempo nos cubículos de vidro. E o ar sombrio que vi naquele dia em Berlim vejo-o de novo na estante. Há ali um desespero antigo, que sabe a Passchendaele e ao Tratado de Paz de Versalhes, talvez até mais antigo. Aqueles massivos tomos negros - a eles voltarei - são à sua maneira passaportes, e tornaram-se densos porque ao longo dos séculos as pessoas tiveram de coleccionar muitos carimbos oficiais. É evidente que um homem não pode sobrestimar a quantidade de bagagem que é suposto ter, agora que está para se ir embora, agora que tu finalmente ...

Ali estão os historiadores, podem levantar-se e espreitar a nossa vida em família. Não consegues ouvir nada, mas os lábios movimentam-se constantemente atrás do vidro ("Passchendael” ...). 
Lembra-me aquela história de um edifício velho de escritórios (uma história verdadeira de fantasmas), um edifício com retratos de cavalheiros há muito falecidos pendurados na parede atrás da vidraça, e uma manhã os empregados do escritório depararam com uma névoa dentro do vidro. Os mortos tinham começado a respirar durante a noite.

A estante ainda resiste. Olha directamente da secção um para a seguinte. Uma pele vacilante, a pele vacilante num rio escuro onde a sala tem de ver a sua própria cara. E virar a cara é proibido.

In: Night Vision / Visão Nocturna (1970), a partir da versão inglesa de Robert Bly

\section{Ir na corrente}

Falar e falar com amigos que vi ouvi por detrás dos seus rostos a corrente arrastando os que querem ir e os que não querem.

E vi uma criatura de olhos colados um ao outro a querer saltar mesmo para o meio da corrente a atirar-se para fora de si sem um tremor numa sede voraz por uma resposta simples.

Rápido e mais rápido a água arrasta

como se fosse um rio que estreita adiante e dispara em rápidos - parei para descansar num sítio como aquele depois de um passeio pelos bosques secos numa tarde de Junho: o transístor trouxe-me as últimas sobre a Sessão Extraordinária: Kosygin, Eban. Um ou dois pensamentos fizeram o seu caminho em desespero. 
Um ou dois homens afogaram-se na aldeia.

E enormes massas de água avançam sob a ponte

suspensa. Aí vem a madeira! Alguns troncos

disparam para diante como torpedos. Outros atravessam-se

de lado, indolentes, e rodopiam desamparados,

e outros de frente virada para as margens do rio

seguem entre pedras e lixo, ficam presos,

e amontoados voltam-se para o céu como mãos entrelaçadas,

orações submersas num rugido ....

Vi ouvi isso de uma ponte suspensa

entre uma nuvem de mosquitos

na companhia de uns quantos miúdos. As suas bicicletas

enterradas em arbustos - só os chifres

de fora.

In: Night Vision / Visão Nocturna (1970),

a partir da versão inglesa de Robert Bly 


\section{Arcos Românicos}

Turistas amontoados no lusco-fusco da grande

igreja românica.

Nave após nave se abria sem perspectiva.

Algumas chamas de velas tremulando.

Um anjo cujo rosto não vi abraçava-me

e o murmúrio dele trespassava-me o corpo:

"Não tenhas vergonha de seres um ser humano, tem orgulho!

Em ti se abre uma nave após outra sem fim.

Nunca serás concluído, e é assim que tem de ser."

Lágrimas cegavam-me

enquanto éramos levados para a intensa piazza iluminada

na companhia de Mr. e Mrs. Jones, Herr Tanaka e Signora Sabatini;

em cada um deles nave após nave se abria sem fim.

In : The Wild Market Square / Feira Livre (1983),

a partir da versão inglesa de Robert Bly 